\title{
Potential Benefits of Implementing Load Control
}

\author{
Marija Ilic, Fellow, IEEE, Jason W. Black, Student Member, IEEE, Jill L. Watz, Student Member, IEEE
}

\begin{abstract}
The design of wholesale electricity markets through deregulation has focused almost exclusively on the development of competitive supply (generation). The demand side of the market has been virtually ignored. Mostly, this is due to the assumption that electricity demand is almost completely inelastic. As a result, deregulated wholesale markets uni versally fail to pass price signals down to the end-users. This paper challenges the assumption of inelastic demand by exploring the potential benefits of implementing a simple load control scheme. This load control scheme allows consumers to shift demand from high priced hours to low priced hours during the day. The benefits to the individual consumer are explored through an example applied to residential air conditioning using price and demand data from California. This example shows that "smart" use of air conditioning can lead to great savings for residential consumers, without sacrificing comfort. The potential for multiple consumers implementing load control to reduce wholesale prices is also examined.
\end{abstract}

Index Terms--Demand Management, Demand Elasticity, Electricity Markets, Load Serving Entity, Load Control

\section{The Problem of Unresponsive Demand}

Two major factors contribute to the problem of unresponsive demand: First, current market designs do not provide price signals to end-use customers to modify their demand; Second, the technical infrastructure required to allow consumers to rapidly and simply modify their usage according to such price signals has not been implemented.

Under the traditional regulated utility structure, most customers are metered monthly and billed a flat average rate for the total amount of electricity used. Hourly variations in the wholesale price of electricity are averaged over the entire month and allocated according to estimated usage profiles for various customer types. The bill that a consumer receives for electricity does not directly correspond to the actual prices during the time of the consumer's actual usage. One clear deficiency with flat rate, average pricing is the lack of price signals to the customer. Without this critical piece of information, consumers have no incentive to change their consumption behavior in response to high wholesale prices or supply shortages and ultimately, market inefficiencies or even failure results.

In order to adjust their electricity consumption according to hourly price variations, consumers must be able to receive the price information, and must have a means to control their usage. Recent advances in communications, information technology, and power electronics have made the

M. Ilic is with the MIT Department of Electrical Engineering and Computer Science, Cambridge, MA 02139 (email: ilic@ mit.edu)

J. Black is with the MIT Engineering Systems Division in the Technology, Management, and Policy Program, Cambridge, MA 02139 (email: jwblack@mit.edu)

J. Watz is with the MIT Engineering Systems Division in the Technology and Policy Program, Cambridge, MA 02139 (email: jwatz@ mit.edu)

This work was originally developed as part of the MIT course 6.689

"Seminar on Power System Modeling, Dynamics, and Control". implementation of load control systems at the residential level feasible both economically and technically [2]. Given the proper market incentives, customers and Load Serving Entities (LSEs) will be willing to invest in the infrastructure to facilitate load control.

\section{The need for control strategies with real-time} metering and prices

To date, price responsive demand has not been realized in the deregulated markets. As a result, when supply is limited, it is easier for generators to exert market power and drive up prices. Enabling price responsiveness can help to mitigate price spikes and market power. Load Serving Entities (LSEs) have the ability to devise contracts with their consumers to control loads during periods when demand is very high, giving the LSE more flexibility to manage price risk. In addition, a more responsive aggregate demand can result in lower wholesale prices which benefits all participants. Figure 1 illustrates the interaction between aggregate power supply from the generators, aggregate demand by the LSE, and LSE/end-use consumer response to price signals. As shown, various LSEs aggregate individual load demand $\left(q\left(x_{i}{ }^{n}, p_{i}\right)\right)$ at set point $x^{n}$ on behalf of their customer base, a mix of residential, commercial and industrial loads (for $n$ loads). An aggregate demand curve $\left(Q^{\mathrm{D}}(\mathrm{p})\right)$ is derived by each LSE based on the individual customer demand curves and contract terms and then bid into the market. A total market demand curve is matched to the supply curve $\left(Q^{S}(p)\right)$ and a market clearing price $\left(\mathrm{P}_{\mathrm{i}}\right)$ and quantity are determined. If the price is high, the LSE and end-user have an incentive to reduce load to lower costs by reducing load either through direct $\left(\mathrm{q}\left(\mathrm{x}_{\mathrm{i}}\right)\right)$ or indirect $\left(\mathrm{y}_{\mathrm{i}}\right.$ : control signal from the LSE to the load) control of end-use equipment. ${ }^{1}$ The degree of load control and demand reduction will be based on the types of contracts setup between the LSE and its customers.

Figure 1 - Interaction between aggregate supply and aggregate demand

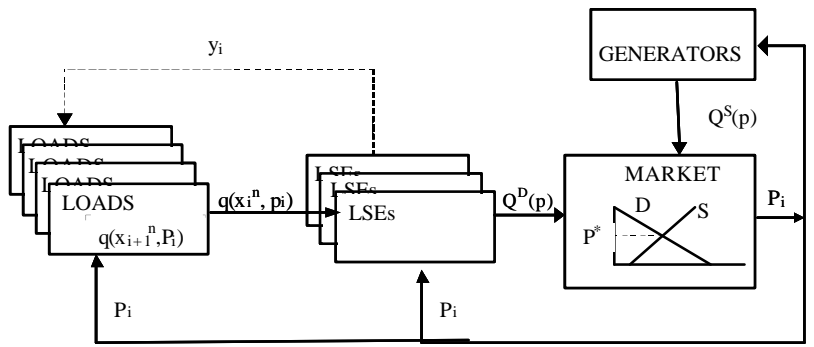

The price signal provides incentives to the end-use customer to reduce load (i.e., turn the thermostat up on an air conditioning unit) at peak times of the day when prices are high. This can be done either independently (automatically or manually) by the consumer, and/or by the load serving entity

\footnotetext{
${ }^{1}$ The price signal could be an actual real-time signal when there is a multisettlement day ahead and spot market or a day ahead price signal in a single settlement market.
} 
(retail service provider) controlling end-use customer loads through a coordinated optimization scheme (with appropriate contracts). Currently available real-time metering technology can provide these price signals. In the past, this was primarily used only by large consumers due to cost and access limitations. Innovations in information technologies and power electronics, however, have driven down the cost of these metering technologies to the point where they are costeffective for smaller consumers [2]. Implementation of these technologies coupled with smart end-use equipment (such as, HVAC equipment, refrigeration, water heating, etc.) that can respond to price signals and shed load when prices are high, offers a control system to manage load and maintain more stable electricity market prices.

\section{Effects of Demand Response on Load and Market Price}

In order to illustrate the effect demand response can have on aggregate load and the market-clearing price, an example is presented of a simple thermostat control device used to shift peak load demand for residential air conditioning. In summer months, air conditioning presents the largest portion of peak load in most of the U.S. In California, it accounts for $29 \%$ of the peak demand with residential AC load contributing $14 \%$ and commercial AC load contributing $15 \%$. Because AC is the primary contributor to peak load, it is useful to examine the amount of load shifting or shedding required to have an effect on the market price. A simple control scheme for residential $\mathrm{AC}$ is used as an example to demonstrate the ability of a smart consumer (or AC unit) to respond to rising prices in anticipation of a high peak load price.

The example is presented in two parts. The first part evaluates the level of control required to maintain indoor air temperature within a comfortable range between $68^{\circ} \mathrm{F}$ and $72^{\circ} \mathrm{F}$ when the outside temperature is $88^{\circ} \mathrm{F}$ over a typical $14-$ hour demand period and calculates the cost savings compared to maintaining an $\mathrm{AC}$ unit at a constant temperature of $70^{\circ} \mathrm{F}$ throughout the entire period ${ }^{2}$. The results show the potential savings for an individual customer for a single summer day in California where there were significant price spikes. Other elements of the residential load and simple behavioral changes that can also contribute to shifting peak load and reducing consumer cost using relatively inexpensive and commercially available control technologies to manage load are also examined.

The second part of the example examines the total potential for peak shifting by extrapolating the results for a single consumer to multiple consumers. The resulting reduction in the overall peak demand is used to estimate the possible effect on the overall wholesale market prices in CA on a typical summer day for various levels of penetration of air conditioning load control.

\footnotetext{
${ }^{2}$ Normal cycling of the thermostat will cause the temperature to "naturally" vary around the ideal, however this cycling will occur such that the amount of power consumed will be evenly distributed among each hour.
}

\section{Potential for peak load shifting among residential consumers - single household}

The following example illustrates the potential peak load savings (both economic and power) resulting from using a load control scheme for air conditioning in a typical household. The control scheme, based on the control model outlined in the paper by Constantopoulos, Schweppe, and Larsen [1], uses real pricing data from the CA ISO for a summer day last year (2000) to control the output of the air conditioning system for optimal cost savings. The result provides the potential economic savings a consumer could have enjoyed from employing such a control scheme, as well as the resultant reductions in peak load power usage.

The Consumer's objective is to minimize the cost of air conditioning while maintaining the indoor air temperature within a certain range.

$$
\begin{aligned}
& \operatorname{Min}_{e} C_{a c}=\sum_{i} P_{i} * q_{i} \\
& \text { s.t. } \\
& 0 \leq q_{i} \leq q^{\max } \\
& T^{\text {min }} \leq T_{i} \leq T^{\max } \\
& \text { where: }^{\text {min }}=\mathrm{T}^{\text {ideal }}-\mathrm{d} \\
& \mathrm{T}^{\text {max }}=\mathrm{T}^{\text {ideal }}+\mathrm{d} \\
& \mathrm{d}^{\mathrm{d}}=\text { Acceptable temperature deviation } \\
& \mathrm{q}_{\mathrm{i}} \text { - energy }(\mathrm{kWh}) \text { consumed for air conditioning in hour } \mathrm{i} . \\
& \mathrm{P}_{\mathrm{i}} \text { - price of electricity }(\$ / \mathrm{kWh}) \text { in hour } \mathrm{i} \text {. }
\end{aligned}
$$

The hourly household temperature is determined by (Table 1 presents the parameters and definitions.):

$\mathrm{T}_{\mathrm{i}+1}=\varepsilon \mathrm{T}_{\mathrm{i}}+(1-\varepsilon)\left(\mathrm{T}^{\mathrm{o}}-\eta^{*} \mathrm{q}_{\mathrm{i}} / \mathrm{A}\right)$

To maintain a constant indoor temperature at $70^{\circ} \mathrm{F}$ with an outside temperature of $88^{\circ} \mathrm{F}$, i.e., $\left(\mathrm{T}^{\mathrm{o}}{ }_{\mathrm{i}}-\eta^{*} \mathrm{q}_{\mathrm{i}} / \mathrm{A}\right)=\mathrm{T}_{\mathrm{i}}=70^{\circ} \mathrm{F}$, the power required is calculated to be $\mathrm{q}=1.008 \mathrm{KWh}$. Similarly, for an outside temperature of $75^{\circ} \mathrm{F}$, the power required is $0.28 \mathrm{KWh}$ and for an outside temperature of $95^{\circ} \mathrm{F}$, the required power is $1.4 \mathrm{KWh}$.

TABLE 1. Parameters and Values of Residential AC Control Model

\begin{tabular}{|l|l|l|}
\hline Variable & Value & Description \\
\hline $\mathrm{T}_{0}$ & 70 & $\left({ }^{\circ} \mathrm{F}\right)$ initial t emperature \\
\hline$\eta$ & $2.5^{*}$ & $(\mathrm{COP})$ efficiency of AC \\
\hline $\mathrm{q}_{\mathrm{i}}$ & & Power output of AC in hour i \\
\hline $\mathrm{q}_{\max }$ & 3.5 & $(\mathrm{Kw})$ maximum power output of AC \\
\hline$\varepsilon$ & $0.96^{*}$ & System inertia $\quad[=$ exp $(-\tau / \mathrm{TC})]$ \\
\hline $\mathrm{TC}$ & $25^{*}$ & $(\mathrm{hr})$ Time Constant for home \\
\hline$\tau$ & $1^{*}$ & $(\mathrm{hr})$ duration of control period \\
\hline $\mathrm{A}$ & $0.14^{*}$ & $\left(\mathrm{KW} /{ }^{\circ} \mathrm{F}\right)$ Thermal Conductivity \\
\hline $\mathrm{T}^{\circ}$ & $88^{\circ}$ & Outside Temp $\left({ }^{\circ} \mathrm{F}\right)$ \\
\hline $\mathrm{T}_{\mathrm{d}}$ & $70^{\circ}$ & Desired household Temp $\left({ }^{\circ} \mathrm{F}\right)$ \\
\hline $\mathrm{T}_{\max }$ & $72^{\circ}$ & Highest acceptable household Temp $\left({ }^{\circ} \mathrm{F}\right)$ \\
\hline $\mathrm{T}_{\min }$ & $68^{\circ}$ & lowest acceptable household Temp $\left({ }^{\circ} \mathrm{F}\right)$ \\
\hline $\mathrm{T}_{\mathrm{i}}$ & $70^{\circ}(\mathrm{i}=0)$ & Current household Temp $\left({ }^{\circ} \mathrm{F}\right)$ \\
\hline
\end{tabular}

*Parameters from [1] 
Table 2 compares the results of applying a load control scheme to the AC versus the base case of allowing the AC to run on a single thermostat setting. It is assumed that the consumer is indifferent to indoor temperature fluctuations between $68^{\circ}$ and $72^{\circ} \mathrm{F}\left(\mathrm{T}^{\text {ideal }}=70^{\circ}, \mathrm{d}=2^{\circ}\right)$. The price data from a single summer day (June 29, 2000) in Burbank, California where the temperature reached $88^{\circ} \mathrm{F}$, is used.

As shown, during the 6 highest price hours of the day (hours 13-18), a $83 \%$ reduction in peak demand for air conditioning can be achieved by load shifting without moving outside the indifferent temperature range. It is observed that a single residential consumer could have saved $37 \%$ off their cost of energy for air conditioning alone. This does not include any effects from peak price reductions due to lowering the overall peak load (many consumers would have to employ such a scheme for this effect to become significant).

There is, however, a moderate increase in consumption in the hours before and immediately after the peak hours; with the highest consumption at beginning and end of the control period. The overall energy consumption is nearly equivalent for the fourteen hour period using the load control scheme.

TABLE 2. Comparison Of Control Scheme To Base Case

\begin{tabular}{|r|r|r|r|r|r|r|r|}
\hline \multicolumn{3}{|c|}{} & \multicolumn{2}{l|}{ Continuous Cycling } & \multicolumn{3}{l|}{ Load Control } \\
\hline $\mathrm{Hr}$ & $\begin{array}{c}\text { Price } \\
(\$ \mathrm{MWh})\end{array}$ & Temp & $\begin{array}{l}\text { Output } \\
(\mathrm{KWh})\end{array}$ & Cost (mils) & Temp & $\begin{array}{l}\text { Output } \\
(\mathrm{KWh})\end{array}$ & Cost (mils) \\
\hline 8 & $\$ 119.99$ & 70 & 1.008 & 120.95 & 68.15 & 3.600 & 431.97 \\
\hline 9 & $\$ 174.17$ & 70 & 1.008 & 175.57 & 68.00 & 1.320 & 229.85 \\
\hline 10 & $\$ 250.00$ & 70 & 1.008 & 252.00 & 68.00 & 1.120 & 280.00 \\
\hline 11 & $\$ 358.39$ & 70 & 1.008 & 361.26 & 68.00 & 1.120 & 401.40 \\
\hline 12 & $\$ 636.97$ & 70 & 1.008 & 642.06 & 68.64 & 0.229 & 146.06 \\
\hline 13 & $\$ 749.99$ & 70 & 1.008 & 755.99 & 69.41 & 0.000 & 0.00 \\
\hline 14 & $\$ 749.99$ & 70 & 1.008 & 755.99 & 70.15 & 0.000 & 0.00 \\
\hline 15 & $\$ 749.99$ & 70 & 1.008 & 755.99 & 70.87 & 0.000 & 0.00 \\
\hline $\mathbf{1 6}$ & $\$ 750.00$ & 70 & 1.008 & 756.00 & 71.55 & 0.000 & 0.00 \\
\hline $\mathbf{1 7}$ & $\$ 750.00$ & 70 & 1.008 & 756.00 & 72.00 & 0.296 & 221.86 \\
\hline $\mathbf{1 8}$ & $\$ 749.99$ & 70 & 1.008 & 755.99 & 72.00 & 0.896 & 671.99 \\
\hline 19 & $\$ 749.99$ & 70 & 1.008 & 755.99 & 72.00 & 0.896 & 671.99 \\
\hline 20 & $\$ 627.37$ & 70 & 1.008 & 632.39 & 71.93 & 0.996 & 624.89 \\
\hline 21 & $\$ 413.17$ & 70 & 1.008 & 416.48 & 70.00 & 3.600 & $1,487.40$ \\
\hline & Totals - & & $\mathbf{1 4 . 1 1 2}$ & $\mathbf{7 , 8 9 2 . 6 6}$ & & $\mathbf{1 4 . 0 7 3}$ & $\mathbf{5 , 1 6 7 . 4 1}$ \\
\hline
\end{tabular}

For simplicity, this example assumes a constant outdoor temperature of $88^{\circ} \mathrm{F}$ over the entire 14 -hour period. The amount of potential shifting can actually be enhanced, depending upon the time it takes for the temperature to change (i.e., it will take less power at the end of the cycle to bring the temperature down from the upper thermostat bound if the outside temp has also come down during that time and less initial energy to achieve the low temperature bound if it is not yet at the hottest time of the day.) The total energy consumption would actually be lower in a more detailed example that accounted for daily fluctuations in outdoor temperature.

\section{Other options for reducing the overall peak residential load}

The following scenario provides additional examples of the potential effect of load shifting for various types of residential end-use loads. Table 3 provides a list of common residential appliances and their contributions to peak and offpeak loads. ${ }^{3}$ For these examples, calculations are based on the following assumptions:

- 6 Peak hours per day

- $\quad 1 / 3$ of the average total household consumption is during the 6 peak hours

- Average Household consumption is $2100 \mathrm{KWh}$ per month during the summer ${ }^{4}$.

- Assumes the following breakdown of peak (6hrs/day) to off peak (18hrs/day) usage for appliances ${ }^{5}$ :

Table 3 - Load Composition - Residential Appliances ${ }^{6}$

\begin{tabular}{|l|l|l|l|}
\hline Appliance: & Monthly Use (kW) & $\%$ peak & $\%$ Off-Peak \\
\hline Air Conditioner & 642 & $40 \%$ & $60 \%$ \\
\hline Water Heater & 513 & $25 \%$ & $75 \%$ \\
\hline Refrigerator & 112 & $25 \%$ & $75 \%$ \\
\hline Range & 375 & $50 \%$ & $50 \%$ \\
\hline Freezer & 100 & $25 \%$ & $75 \%$ \\
\hline Dryer & 85 & $60 \%$ & $40 \%$ \\
\hline Washer & 12 & $60 \%$ & $40 \%$ \\
\hline Dishwasher & 12 & $60 \%$ & $40 \%$ \\
\hline
\end{tabular}

Based on the above assumptions, the following reductions in peak load are possible:

1) Shifting $50 \%$ of peak use of washer, dryer, and dishwasher to off peak times leads to a $4 \%$ reduction in peak household usage

2) Using Load control for Air Conditioning leads to a $28 \%$ reduction in peak household usage

3) Using similar load control devices for water heater, refrigerator, and freezer leads to a $20 \%$ reduction in peak household usage

4) Incorporating all of the above leads to a $52 \%$ reduction in peak household usage

5) $100 \%$ shift of washer, dryer, and dishwasher leads to a $8 \%$ reduction in peak household usage

6) $100 \%$ shift of washer, dryer, and dishwasher + load controls(2 and 3 ) leads to $56 \%$ reduction in peak household usage.

The above calculations are rough estimates based on assumptions of average consumption, and there is a large variation in actual household usage patterns. Even so, they clearly show the large potential to reduce peak loads through relatively simple changes in usage. Given the proper incentives that real time pricing schemes provide, it is not

\footnotetext{
${ }^{3}$ based on lo ad profile data from Niagara Mowhawk, 2001

${ }^{4}$ Assumes family of four with air conditioning and electric stove and water heater.

5 The assumed breakdown is based on the aggregate load profile from Niagara Mohawk, so that $1 / 3$ of all power is consumed during peak hours. A $25 \%$ to $75 \%$ split indicates uniform usage.

${ }^{6}$ Appliance data from: Otter Tail Power Company Website, May 2001. http://www.otpco.com/home/edu usage.asp
} 
unrealistic to expect dramatic reductions in peak loads. Especially in cases such as California where there are extreme variations in wholesale prices.

\section{Control Technology Implementation}

The potential for reducing peak household consumption during the summer by implementing these few simple steps appears to be quite large. By simply modifying their behavior in washing clothes and dishes, consumers can reduce their peak demand by between 4 to $8 \%$. This would require no additional investment whatsoever, and have a relatively minor impact on consumer utility (quality of life). Manufacturers could easily add timers to washers, dryers, and dishwashers for little additional cost, but there is currently little demand for such features. Current pricing structures (ie flat rate) provide little or no incentives for consumers to modify their behavior, however. Most consumers are not even aware that electricity costs more during certain times of the day.

Switching to a real time pricing scheme would require the installation of automated metering and a communications infrastructure (see [17]), as well as regulatory changes. The potential savings from peak reduction, however, is large enough to pay for the installation of such infrastructure.

Implementing a load control scheme for AC or other energy (vs power) consuming appliances is slightly more difficult, but also feasible. The potential for shifting load from peak hours using such devices is quite large. In addition to the communications infrastructure necessary to implement real time pricing, the controllers themselves will need to be developed, as well as the software to determine the optimal usage profile for the appliances. Programmable thermostats currently exist for $\mathrm{AC}$ and heating, but it would currently be rather difficult for the average consumer to install such a thermostat and link it to his/her computer where a control algorithm would automatically program the usage according to the day's hourly electricity prices. Standardization of this equipment is necessary so that consumers can "plug and play" with little or no hassle.

Incorporation of controls on refrigerators, freezers, and water heaters would be relatively simple and low cost. Once again, the lack of a demand for such controllers is the main obstacle to manufacturers including them as a standard feature with these appliances.

\section{Extrapolated Effect of Controlling Residential AC on Market Price}

Small adjustments in end-use appliance usage enabled by simple control schemes and real-time pricing can have a tremendous potential effect on electricity market prices. Using the simple residential AC load shifting example and applying it to the entire CA market demonstrates this point. The summer 2000 peak load in CA was approximately 51,000 MW. The residential AC portion of the peak CA load is $14 \%$. Extending the calculated $83 \%$ load shift in air conditioning to the entire residential load over a 6-hour peak, we calculate a system wide peak load reduction of $12 \%$ (15). It is not necessary for everyone to shift load, however, because too much deferment would create new, even higher peaks in the morning and early evening. Thus, it is useful to find the percentage of the AC load that can best flatten out the peak over the higher demand part of the day and reduce the load factor. Figure 2 shows the effect of reductions between 20 and $35 \%$ in AC peak load on the daily demand curve. It is clear that a $35 \%$ reduction which lowers the system-wide peak by almost $6 \%$ is effective in smoothing out the peak.

Figure 2. Effect of Load Shifting on Aggregate Demand

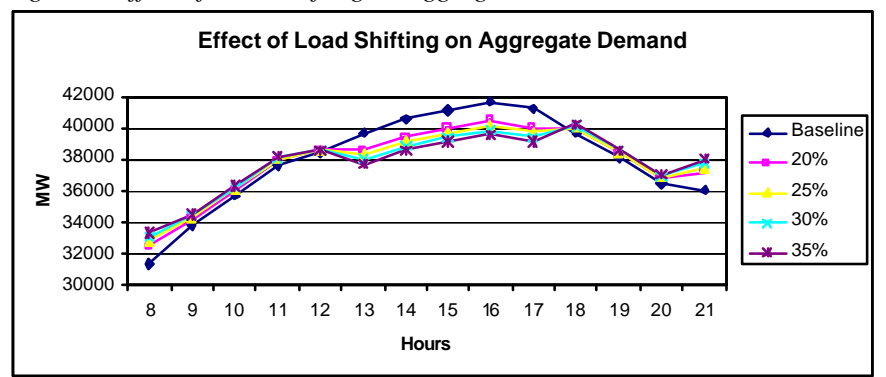

To further illustrate how a responsive demand could have helped lower peak wholesale market prices on a high demand day in CA, prices for the reduced demand during peak hours were estimated based on supply bid data from the CA Power Exchange. Figure 3 shows the unconstrained market clearing price and system load for June 29, 2000, a day where the wholesale market hit the $\$ 750 / \mathrm{MW}$ price cap from 1:00 PM through 7:00 PM. Figure 4 shows the supply bid curve and the corresponding market prices for a 20, 25, 30 and $35 \%$ reduction in AC peak load for hour 16:00. As shown, the price would drop from $\$ 750$ to $\$ 424 / \mathrm{MWh}$ at $20 \%$ and to $\$ 114$ at $35 \%$. By simply shifting load from the four hours (13:00 through 16:00) the resulting market cost savings would range from $\$ 50 \mathrm{M}$ at $20 \%$ to $\$ 100 \mathrm{M}$ at $35 \%$. However, the cost savings would be slightly off-set by higher prices in the hours where additional load is picked-up (shifted).

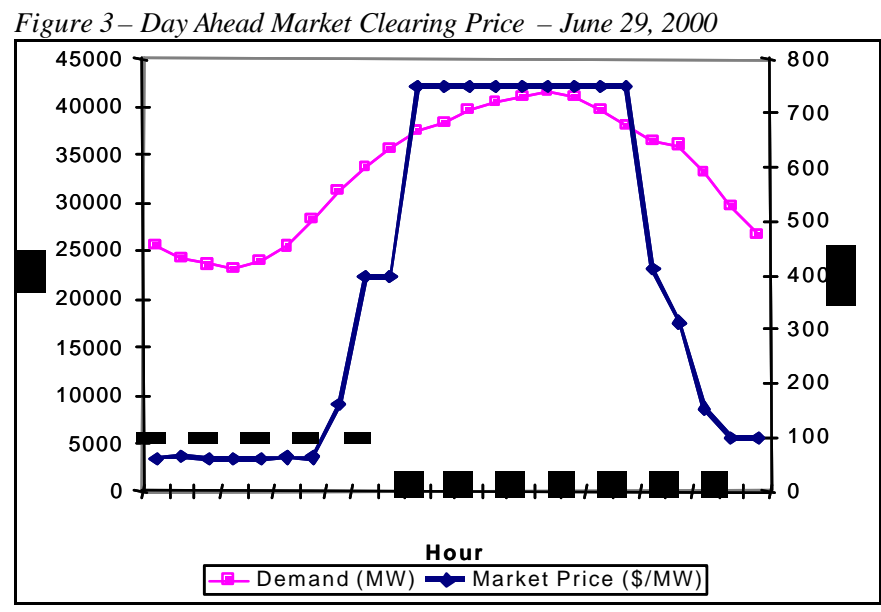


Figure 4 - Effects of Load Shifting on Market Clearing Price

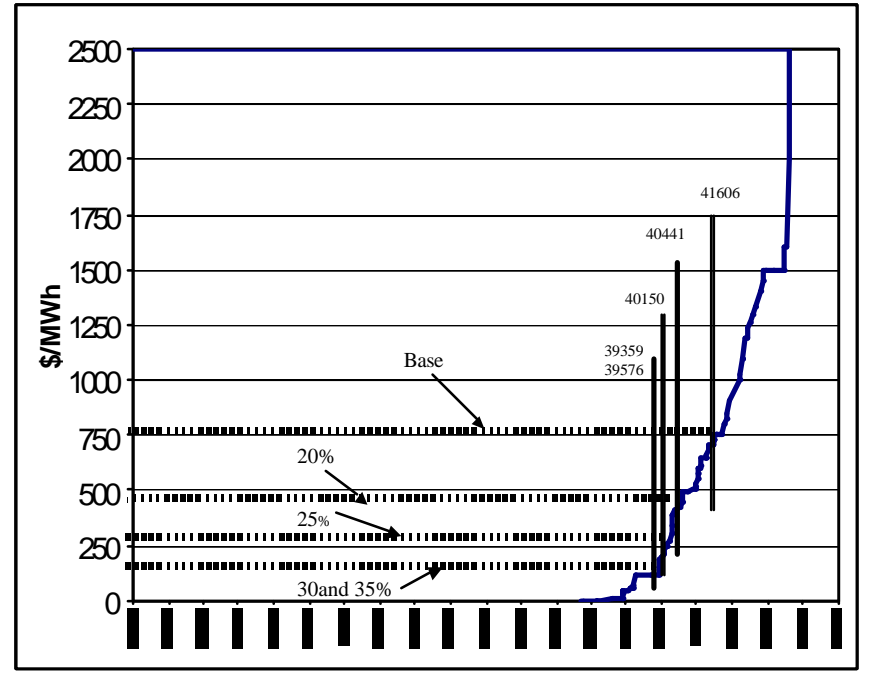

\section{Conclusions}

This paper asserts that load management can have a dramatic effect on the utility bill for individual consumers and potentially on wholesale electricity prices if markets encourage price responsive demand and consumers are able to predictably respond to high price signals by shifting load. Exposing customers to real-time pricing provides the needed incentive to create demand elasticity.

As shown for an anticipated price profile, a residential customer can determine optimal (least cost) consumption patterns without forsaking comfort (in this case: a cool house on a hot day). When this type of peak shifting behavior is conducted on a more aggregated level, e.g., by an LSE through the use of appropriate controllers, the aggregate reduction can result in a lower hourly wholesale electricity price. The examples provided in this paper present a simple case illustrating the important effects of load response to anticipated electricity price.

It is important to note that the dynamics of a real-time market and the impact of various market structures on price are not accounted for and are beyond the scope of this paper. Further research is being conducted to explore the dynamic effects of active demand side bidding and load control on markets and the responsiveness of the physical power system. For example, some areas of future research include: the effect of load response on price volatility and generator/LSE market power; bidding and financial contract strategies for generators and LSEs; and dynamic power systems control and technical infrastructure protocols for reliability. Research in these areas is currently underway at the MIT Laboratory for Energy and the Environment ${ }^{7}$.

Additional research related to this subject is needed on a variety of levels to provide a sound basis for future policies and investments. Of particular importance is the role of state

\footnotetext{
${ }^{7}$ Formerly the MIT Energy Lab (www.mit.edu/energylab/www) and the Center for Environmental Initiatives.
}

and local governments in developing and implementing deregulation policies. In the short-term, government has the ability to conduct pilot studies on the effect of demand responsiveness, load aggregation, and consumer elasticity on market price. Well-designed experiments could be very helpful in fully characterizing consumer demand elasticity, the effects of load aggregation, overall benefits of load response, the infrastructure technologies and costs, and affects on market behavior. These studies could be done in collaboration with LSEs and technology companies interested in analyzing the performance of this system.

Other important questions that need resolution include: understanding the economic trade-off between investments in centralized generation and transmission, and investments in well-designed control schemes that enable distribution-side demand responsiveness. Distributed generation is also essential to optimizing future investments in power system infrastructure.

\section{Acknowledgements}

The authors greatly appreciate the contributions of Elena Fumagalli and Poonsaeng Visudhiphan for their work on the original paper [8] on which this work is based.

\section{References:}

1. Constantopoulos, P., Schweppe, F. and Larson, R., "ESTIA: A Realtime Consumer control Scheme for Space Conditioning Usage Under Spot Electricity Pricing." Computers Operations Research, vol 19, no. 8, pp 751-765, 1991.

2. Black, Jason W. Ilic, Marija, "Survey Of Technologies And Cost Estimates For Residential Electricity Services", Accepted for Publication. IEEE Proceedin gs, Summer 2001

3. Data from California Energy Commission, Richard Rohre, Energy Demand and Forecasting Group.

4. Supply-Demand bid curve data June 29, 2000 from the California Power Exchange http://www.calpx.com

5. Unconstrained hourly market clearing price from the California ISO website. http://www.caliso.org

6. Fumagalli, E., Black, J., Ilic, M., Vogelsang, I., A Reliability Insurance Scheme for the Electricity Distribution Grid, MIT Energy Lab Working Paper EL 01-001 WP, January 2001 and IEEE Proceedings, PES Summer 2001.

7. Fumagalli, E, Quality of Service: Comparing the Italian Regulatory scheme with an Insurance-Based Approach, Gas and Electricity Forum, Scuola Superiore E. Mattei, Milano, Italy, 21-22 June 2001

8. Watz, J, Fumagalli, E., Black, J., Visudhiphan, P, Ilic, M Understanding Demand: The Missing Link in Efficient Electricity Markets, MIT Laboratory for Energy and the Environment Working Paper, August 2001.

9. Radar, N. Hempling, S, Promoting Competitive Electricity Markets Through Community Purchasing: The role of Municipal Aggregation", American Public Power Association, January 2000.

10. California Public Utility Commission- Office of the Ratepayer Advocate. Monthly summary choosing direct access. April, 2001 http://www.cpuc.ora.gov.

11. Massachusetts DOER, 2001

12. Pennsylvania Public Utility Commission, Office of the Ratepayer Advocate. Monthly Data on customers switching from default utility. April, 2001.

13. Ilic M., Skantze P., Yu C.N., Fink L., Cardell J., Power Exchange for frequency control (PXFC), Proceedings of the IEEE PES Winter Meeting, New York, NY, January 1999.

14. Cox, J., Rubinstein, M., (1985), Options Markets, Prentice Hall, New Jersey. 
15. Bertsekas, D., (1987), Dynamic Programming: Deterministic and Stochastic Models, Prentice-Hall, New Jersey.

16. Pindyck. R.S., Rubinfeld, D.L.,(1997), Microeconomics $4^{\text {th }} e d$., Prentice-Hall, New Jersey.

17. Hull, J.C., (1999), Options, Futures, and Other Derivatives, $4^{\text {th }}$ ed. Prentice-Hall.

18. Skantze, P., Gubina, A. F., Ilic, M.D., Bid-based Stochastic Model for Electricity Prices: the Impact of Fundamental Drivers in Market Dynamics, The MIT Energy Lab Technical Report EL 00-004, MIT, November 2000.

19. Wagner, M., Hedging Optimization Algorithms for Deregulated Electricity Markets, Master of engineering Thesis, EECS Department, MIT, June 2001.

\section{Biographies}

Marija M. Ilic is a Senior Research Scientist in the Department of Electrical Engineering and Computer Science at MIT, where she teaches several graduate courses in the area of electric power systems and heads research in the same area. She has twenty years of experience in teaching and doing research in this area. Prior to coming to MIT in 1987, she was an Assistant Professor at Cornell University, and tenured Associate Professor at the University of Illinois at Urbana Champaign. Her main interest is in the systems aspects of operations, planning and economics of electric power industry. Dr. Ilic received her M.Sc. and D.Sc. degrees in systems science and mathematics from Washington University in St. Louis.

Jason W. Black is pursuing his Ph.D. in Technology, Management, and Policy at MIT, with a concentration in electric power systems and regulation. $\mathrm{He}$ received a B.S. degree in Electrical Engineering and a B.A. in Government and International Studies from the University of Notre Dame in 1994.

Jill Watz is pursuing her M.S. in the Technology and Policy Program at MIT, with a concentration in electric power systems and market design. She received a B.S. degree in Chemical Engineering from the University of California, San Diego in 1986. 